\title{
DEVELOPMENT OF PROCESS INDUCED RESIDUAL STRESS DURING FLOW FORMING OF TUBULAR 15-5 MARTENSITIC STAINLESS STEEL
}

\author{
Saber Khayatzadeh \\ Advanced Forming Research Centre, \\ Strathclyde University, \\ Renfrew, Glasgow, PA4 9LJ, UK \\ Joe F. Kelleher \\ ISIS Pulsed Neutron \& Muon Source, \\ Harwell Campus, Didcot, Oxfordshire, OX11 0QX, UK
}

\author{
Shanmukha Rao Moturu \\ Advanced Forming Research Centre, \\ Strathclyde University, \\ Renfrew, Glasgow, PA4 9LJ, UK \\ Salah Rahimi \\ Advanced Forming Research Centre, \\ Strathclyde University, \\ Renfrew, Glasgow, PA4 9LJ, UK
}

\section{ABSTRACT}

Flow forming is a near net shape process for manufacturing of dimensionally accurate hollow components such as shaft in gas turbines, that is currently at its development stage for aerospace industry. The process has several advantages such as reducing material wastage, extremely fast manufacturing time, and eliminating extra manufacturing processes such as machining. Due to the nature of this complicated cold deformation process, significant magnitude of residual stress is introduced into the component. Understanding the magnitude and distribution of residual stress is essential to tailor the flow forming process to achieve parts within dimensional tolerances and desired mechanical properties. The present research is aiming to explore the generation and evolution of residual stress at various stages of flow forming process in a tubular component made from martensitic $15 \mathrm{Cr}-5 \mathrm{Ni}$ stainless steel, using different techniques of neutron scattering, $x$-ray diffraction (XRD) and hole-drilling based on electronic speckle pattern interferometry (ESPI).

Residual stress measurements were carried out in preformed and flow formed components at surface, near-surface and in the bulk of components using XRD, ESPI based hole-drilling and neutron diffraction techniques. These measurements were conducted at different levels of reduction in the thickness of the original part (i.e. after $20 \%$ and $40 \%$ ), by applying identical forming parameters for all samples. The XRD results show significant change in hoop and axial residual stress levels with a reduction in the wall thickness. This is more pronounced for the axial component where the average stress switches from relatively high tensile $(\sim 450 \mathrm{MPa})$ in the original part to significant compressive stress $(\sim-600 \mathrm{MPa})$ in the formed part, after $20 \%$ of reduction. The bulk residual stress components measured in the middle of thickness of the parts, using neutron scattering, show a general increase in the magnitude of residual stress by higher level of deformation (i.e. reduction in the wall thickness). The measured bulk stress components through the thickness were tuned to tensile after reducing the wall thickness by $40 \%$. The results of XRD and neutron diffraction stress measurements suggest that the residual stress along the length of the samples (i.e. axial direction) is consistent with $\pm 800 \mathrm{MPa}$ and $\pm 400 \mathrm{MPa}$ after $20 \%$ and $40 \%$ reduction by forming process, respectively.

The results of ESPI based hole-drilling show tensile hoop residual stress $(\approx 600 \mathrm{MPa})$ and an abrupt fluctuation (i.e. tension-compressive-tension) in the axial residual stress near the surface of the part following flow forming. The stresses measured by ESPI based hole-drilling are complementary to the results of the XRD on surface and neutron diffraction in the bulk to reconstruct the residual stress profile form the surface through to the bulk.

\section{INTRODUCTION}

The automotive, aerospace and power generation industries are increasingly intending to reduce manufacturing cost by reducing material's wastage and the time spent on production. Flow forming is a process that can potentially address these industrial challenges. The process has several advantages such as reducing material wastage (chip-less), extremely fast manufacturing time, produce near net shape parts and no need for further machining to achieve the final geometry. In the flow forming process a hollow tubular part, namely "preform", is mounted and clamped on a rotating mandrel, where three rollers arranged circumferentially around the mandrel forcing the preform to move axially along the rotating mandrel as shown in Error! Reference source not found.

Several parameters are involved in the flow forming process to achieve a component within dimensional tolerances, with a good surface finish and minimised tangential flow to prevent excessive thickness reduction [1]. These parameters are classified into five groups including process, working, tooling, machine and workpiece parameters [1]-[3].

One of the most important factors in flow forming is feed ratio, that is described as the ratio of the roller feed rate to the spindle speed [3]-[6]. Several studies [3]-[9] have been conducted on flow forming of different materials to form parts without defects and with homogenous microstructures. It was concluded that increasing or decreasing the feed ratio may result in the formation of various defects such as non-uniform thickness, reduction in diameter, rough surface, tearing, cracking 
with an increase in feed ratio, excessive material flow in an outward direction with a decrease in feed ratio [3].

Wong et al [4] studied the influence of spinning ratio and roller path on the development of defects, such as buckling, wrinkles and cracks. The study claims that the defects in the components can be avoided by choosing a suitable roller path. Also, spinning ratio, which is the ratio of the preform diameter to the mandrel diameter, plays an important role as the higher ratio makes the process harder [4]. Cutting depth also is crucially important as small depth may result in fish scaling on the surface and large depth may result in highly strained roller profiles [9].

In an investigation conducted by Roy et al [10], on the development of plastic deformation, it was shown that the local plastic strain increases faster at the roller interface compared to that of the mandrel interface, as the reduction in the thickness progresses with flow forming. These differential gradients in plastic deformation through the thickness may be one of the main sources of the generation of residual stresses [2], [3], [11]. Overall, a significantly high magnitude of residual stress is generated in the component.

In a recent study conducted by Tsivoulas et al [3], the generation of residual stresses during flow forming process of a $\mathrm{Cr}-\mathrm{Mo}-\mathrm{V}$ ferritic steel was investigated using XRD and neutron diffraction. In this approach, which was the first one in its kind, the influence of different parameters such as the level of wall thickness reduction, feed rate, and roller geometry on residual stresses was explored. It was concluded that a flow forming process with a high feed rate, small percentages of thickness reduction, and low contact angle rollers, on a preform with low hardness results in low levels of residual stress.

Limited number of experimental data [3], [12]-[14] are available to explain the influence of flow forming parameters on the generation and distribution of process induced residual stress during incremental flow forming. In the present research, number of passes and magnitude of reduction in each pass are chosen to be investigated to understand their potential effects on the magnitudes and distribution of residual stress in the formed component.

\section{NOMENCLATURE}

$\begin{array}{ll}d & \text { Strained lattice parameter } \\ d_{0} & \text { Unstrained lattice parameter } \\ E & \text { Elastic modulus } \\ \varepsilon & \text { Elastic strain } \\ v & \text { Poisson's ratio } \\ \sigma_{x x}, \sigma_{y y} \text { and } \sigma_{z z} & \text { Stress components } \\ \varepsilon_{x x}, \varepsilon_{y y} \text { and } \varepsilon_{z z} & \text { Strain components }\end{array}$

\section{EXPERIMENTAL PROCEDURE}

\subsection{MATERIAL AND MANUFACTURING}

The material used in this study was a martensitic $15 \mathrm{Cr}-$ $5 \mathrm{Ni}$ precipitation-hardened (15-5 $\mathrm{PH}$ ) stainless steel in a form of solid cylinders. This grade of steel is known to provide high strength, good corrosion resistance and good toughness. The nominal chemical composition of the material is given in Table 1. The material was supplied by Neo-Nickel ltd (UK), in a solution annealed condition (i.e. $30 \mathrm{mins}$ at $1038^{\circ} \mathrm{C}$ followed by air cooling to room temperature). To increase the formability of the as-received material, further in-house heat treatment was conducted at $760^{\circ} \mathrm{C}$ for 2 hours, and $621^{\circ} \mathrm{C}$ for 4 hours followed by air cooling to room temperature.

The preforms were machined from the heat treated solid cylinders to achieve samples with inner diameter of $140 \mathrm{~mm}$, thickness of $15 \mathrm{~mm}$, and length of $150 \mathrm{~mm}$. Two parts were flow formed through a single pass one reduced to $20 \%$ and the other to $40 \%$ of the initial thickness, as shown in Figure 2 . Table 2 summarises the details of the geometries of both the preform and flow formed components.

Since the flow forming parameters have a significant influence on residual stress distribution, identical parameters are applied for manufacturing of both parts for the sake of consistency. The parts were manufactured using forward flow forming process in which the directions of both the rollers and material's flow are identical.

\subsection{X-RAY DIFFRACTION}

The XRD residual stress measurements were carried out using a PROTO-LXRD diffractometer and the $\sin ^{2} \psi$ method [15]. An acceleration voltage of $30 \mathrm{kV}$ and $25 \mathrm{~mA}$ current were applied to generate the XRD using a $\mathrm{Cr}-K_{\alpha}$ tube with a wavelength of $(\lambda)=2.291 \mathrm{~nm}$. The stresses were calculated from the strains of the $\{211\}$ Bragg's reflection at $156.4^{\circ}(2 \theta)$ Bragg angle, assuming the elastic Young's modulus of E=200 GPa and Poisson's ratio of $v=0.3$. For each sample, the measurements were performed along hoop and parallel to the forming direction (i.e. axial) at several points. For each point in both directions, 11 measurements with $3 \mathrm{~s}$ exposure time for each measurement were performed. A round collimator with $1 \mathrm{~mm}$ diameter and eleven $\psi$-off set angles in the range of maximum $\pm 33^{\circ}$ were employed.

\subsection{HOLE-DRILLING BASED ON ESPI}

ESPI based hole-drilling technique was used to measure hoop and axial residual stress components on the sample subjected to $40 \%$ reduction in thickness (sample 3 ). The ESPI based hole-drilling method of residual stresses measurement provides information from near surface (i.e. $30 \mu \mathrm{m}$ to $1 \mathrm{~mm}$ depth) that is beyond the penetration depth of the XRD, and below the resolution of neutron diffraction. XRD and neutron diffraction methods were carried at the same location to compare reconstruct the full stress profile from the surface through the near surface to the bulk of the sample. An image of experimental set up of the hole-drilling process is shown in Figure 3. This was carried out using a PRSIM system manufactured by Stresstech, using a monochromatic laser with $532 \mathrm{~nm}$ wavelength as a light source for illumination. The endmills used for these measurements were $1.8 \mathrm{~mm}$ carbide coated drills. Images were recorded during each step of incremental hole-drilling and subsequently the surface displacement caused by material 
removal resulted during drilling were measured. The strains were evaluated based on the measured surface displacement, and the measured strains were then used for inverse calculation of residual stresses using integral method, assuming the Young's Modulus of E=200 $\mathrm{GPa}$ and Poisson's ratio of $v=0.3$.

\subsection{NEUTRON DIFFRACTION}

The neutron diffraction technique was used to measure the residual stress in both pre-formed and flow formed components using the ENGIN-X diffractometer at the ISIS spallation source located near Oxford, UK. The layout of the ENGIN-X instrument at ISIS are given in [16]. At ISIS, accelerated 'bunches' of high-energy protons from a synchrotron ring, collide with a heavy atomic target to generate white beams of neutrons in sharp pulses. The polychromatic wavelength neutrons pass through a moderator to achieve thermal equilibrium, then guided to the experimental instruments through a consecutive set of curved and rectangular guides, slits or jaws, sample, collimators and finally detectors. The slits define the neutron beam cross section. The sample is placed with the scattering vector (Q-vector) bisecting the incident and diffracted neutron beams.

The counting time is the time allowed to obtain statistically a high-quality diffraction pattern from exposure of the measurement point to the neutron beam. The minimum given counting time for each point for this experiment was approximately 20 minutes, with a gauge volume of $2 \times 2 \times 2 \mathrm{~mm}^{3}$. Theodolite and laser scanners are used for the positioning of the un-strained samples for the determination of $d_{0}$, and the samples on the instrument table.

Generally, measurements of strain in tubular samples require at least six directions to determine the full stress tensor. However, it was assumed that the directions of principal stresses were aligned with the sample axes and therefore the required minimum numbers of measurements of strains were reduced to three including parallel to the axial, hoop and radial directions. The neutrons diffracted from a given gauge volume provide an average of elastic strain. The change in the elastic strain is determined from the equation below.

$$
\varepsilon=\frac{\left(d-d_{0}\right)}{d_{0}}
$$

Where $d$ is the strained lattice parameter, and $d_{0}$ is an unstrained lattice parameter assumed to be independent of direction. Stress-free sample with dimensions of $4 \mathrm{~mm} \times 4 \mathrm{~mm} \times$ $8 \mathrm{~mm}$, aligned with axial, hoop and radial directions respectively, were manufactured from the preform part using Electrical Discharge Machin (EDM). The stresses in three orthogonal directions were calculated from the measured strains of (222) (311), (220), (200) and (111) crystallographic planes according to the equations below.

$$
\begin{aligned}
& \sigma_{x x}=\frac{E}{(1+v)(1-2 v)}\left[(1-v) \varepsilon_{x x}+v\left(\varepsilon_{y y}+\varepsilon_{z z}\right)\right] \\
& \sigma_{y y}=\frac{E}{(1+v)(1-2 v)}\left[(1-v) \varepsilon_{y y}+v\left(\varepsilon_{x x}+\varepsilon_{z z}\right)\right]
\end{aligned}
$$

$$
\sigma_{z z}=\frac{E}{(1+v)(1-2 v)}\left[(1-v) \varepsilon_{z z}+v\left(\varepsilon_{y y}+\varepsilon_{x x}\right)\right]
$$

Where E is the Young's modules and $v$ is the Poisson ratio of the material. All lattice parameters were calculated using a Rietveld Analysis [17], in which multiple peaks are fitted over a user defined range. This analysis was performed using the GSAS software in conjunction with the ISIS in house software OPEN GENIE. For each sample, several points were measured in the bulk of the samples along the axial direction in the middle of the wall thickness, and along the radial direction starting from $1 \mathrm{~mm}$ below the outer surface and ended at around $1 \mathrm{~mm}$ from the inner surface. The locations of these measurements for each sample are schematically shown in Figure 4.

\section{RESULTS}

All parts were subjected to residual stress measurements by XRD and neutron diffraction techniques. The results of XRD and neutron diffraction residual stress measurements are presented in Figure 5, Figure 8Figure 6 and Figure 7, respectively for Sample 1, Sample 2 and Sample 3. Bulk residual stress in the preform was only measured in two points by neutron diffraction, one in the middle of the thickness and the other at $3.5 \mathrm{~mm}$ below the outer diameter (Figure $4 \mathrm{a}$ ). The result of measurements on these points shows a very low level of stress in the middle of thickness of the preform (Figure 5). The magnitude of stresses in each direction was increased from 50 $\mathrm{MPa}$ to $100 \mathrm{MPa}$ by moving from the middle of the preform towards the outer surface for $4 \mathrm{~mm}$. The XRD results show high levels of tensile residual stress in both the hoop and the axial directions, on the surface of preform.

After 20\% reduction, the residual stresses were increased throughout the thickness of Sample 2, as shown in Figure 6 . The bulk residual stresses changes from compressive to tensile through the thickness by moving from the outer surface toward the inner surface. The major variation was observed in axial stress that is changing from $-800 \mathrm{MPa}$, at $4 \mathrm{~mm}$ below the outer surface, to $430 \mathrm{MPa}$ at $8 \mathrm{~mm}$ below the outer surface. The hoop and the radial stresses are within the range of $-330 \mathrm{MPa}$ to 200MPa (See Figure 6).

Sample 3 with $40 \%$ reduction is the only sample that was subjected to the ESPI based hole-drilling residual stress measurement in addition to XRD and neutron diffraction techniques. The result of all three measurement techniques are summarised in Figure 7. In contrary to Sample 2, all the measured bulk stress components in sample 3 were tensile. At the proximity of the centre of the thickness, a noticeable increase is observed in the level of residual stress components measured by neutron diffraction (Figure 7). The result of ESPI based holedrilling shows a significant decrease in hoop stress $(\approx 500 \mathrm{MPa})$ changing from $600 \mathrm{MPa}$ at $50 \mu \mathrm{m}$ to $100 \mathrm{MPa}$ at about $1 \mathrm{~mm}$ depth below the outer surface; however, the axial stress fluctuates sharply within this zone from tensile (100MPa) to compressive $(-370 \mathrm{MPa})$ and to tensile again $(500 \mathrm{MPa})$. At $1 \mathrm{~mm}$ below the surface, the measured axial stresses by neutron diffraction is close to the result of ESPI. However, for hoop component, a 
significant difference of $\approx 300 \mathrm{MPa}$ is observed between the results of both techniques at around the same point. This can be due to the fact that the neutron diffraction results have been obtained by averaging the strain data collected from a $2 \times 2 \times 2 \mathrm{~m}^{3}$ volume, that has less resolution compared to the result of ESPI based hole-drilling. Within the $50 \mu \mathrm{m}$ distance below the outer surface, there is a noticeable change in the stresses measured by ESPI compared to those measured by XRD on the surface. The highest change is observed for axial stress which is $-330 \mathrm{MPa}$ on the surface (XRD) and drastically increases to $500 \mathrm{MPa}$ at $50 \mu \mathrm{m}$ below the surface (ESPI).

To investigate the evolution of residual stress during flow forming process, the measured stress components on the surface and through the thickness of all three samples, are compared as shown in Figure 8. All the three components of stresses in the middle of the thickness show an increase from almost zero stress for preform to high tensile stresses by deforming the samples to $40 \%$ reduction. The highest increase is measured for the hoop component which reached $790 \mathrm{MPa}$ after $40 \%$ deformation; the lowest is measured for radial component $(\approx 370 \mathrm{MPa})$. However, the measured stresses on the surface reduced after the first $20 \%$ reduction in the thickness, and then increased after $40 \%$ reduction. The measured hoop stresses for all three cases are tensile; however axial stresses are tensile $(\approx 350 \mathrm{MPa})$ in the preform changed to compressive stresses after deformation (e.g. $\approx-600 \mathrm{MPa}$ with $20 \%$ deformation).

The results of surface residual stress measured by XRD, and the bulk residual stress measured by neutron diffraction in the middle of the thickness, along the length (i.e. axial direction) and perpendicular to the lengths (i.e. hoop direction) of all samples are summarised in Figure 9. Measurements by both techniques were carried out away from the ends of the tubular parts (i.e. at least $45 \mathrm{~mm}$ ) to minimise the edge effect and ensure that the information are captured from flow formed regions. The XRD surface stress results show uniform distribution of both axial and hoop stress on preform (Figure 9 a) and the deformed samples (Figure 9 b, c). As shown schematically in Figure 4, the number of points measured by neutron diffraction was fewer than those measured by XRD. As opposed to the uniform surface residual stress distribution, the bulk stress components measured by neutron diffraction appear to be changing drastically along the axial direction (i.e. flow forming feed direction) of the samples.

\section{CONCLUDING REMARKS}

In this study, residual stress measurements using XRD, ESPI based hole drilling and neutron diffraction were conducted on flow formed samples, and the following major observations are concluded:

- The bulk residual stress components measured by neutron diffraction show an increase in the stress magnitudes with higher levels of deformation by flow forming (i.e. reduction in the thickness). These were $790 \mathrm{MPa}$ and $370 \mathrm{MPa}$ increase in the hoop and radial stress components respectively, after $40 \%$ of reduction in the thickness, in comparison to those of the preform.
- The surface residual stress measured by XRD show a significant decrease in the hoop stress, and high levels of compressive stress in the axial direction (-600MPa) after $20 \%$ reduction in the thickness. After an additional $20 \%$ reduction in the thickness (i.e. 40\%), the stress components were increased toward tensile stresses.

- Residual stresses measured by ESPI based hole-drilling show a good agreement with the results of neutron diffraction within $1 \mathrm{~mm}$ below the outer surface of the sample.

- The more deformation is induced into the sample by reducing the wall thickness, the more harmful tensile stresses with a high magnitude are introduced.

\section{ACKNOWLEDGMENTS}

The authors would like to acknowledge the support provided by the Advanced Forming Research Centre (AFRC), University of Strathclyde, which receives partial financial support from the UK's High Value Manufacturing CATAPULT. The staffs at ENGINE-X, ISIS facilities are thanked for their valuable advices and supports during the residual stress measurements by Neutron Diffraction.

\section{REFERENCES}

[1] M. Runge (D.H. Pollitt, Trans), Spinning and Flow forming. Leifeld Metal Spinning, 1993.

[2] C. Kubilay, "Flow Forming of Aeroengine Materials," 2014.

[3] D. Tsivoulas, J. Quinta da Fonseca, M. Tuffs, and M. Preuss, "Effects of flow forming parameters on the development of residual stresses in $\mathrm{Cr}-\mathrm{Mo}-\mathrm{V}$ steel tubes," Mater Sci Eng A, vol. 624, pp. 193-202, 2015.

[4] C. . Wong, T. . Dean, and J. Lin, "A review of spinning, shear forming and flow forming processes," Int J Mach Tools Manuf, vol. 43, no. 14, pp. 1419-1435, 2003.

[5] M. Jahazi and G. Ebrahimi, "The influence of flowforming parameters and microstructure on the quality of a D6ac steel," J Mater Process Technol, vol. 103, no. 3, pp. 362-366, 2000.

[6] C. C. Wong, T. A. Dean, and J. Lin, "Incremental forming of solid cylindrical components using flow forming principles," J Mater Process Technol, vol. 153, pp. 60-66, 2004.

[7] K. M. Rajan and K. Narasimhan, "An investigation of the development of defects during flow forming of high strength thin wall steel tubes," Pract Fail Anal, vol. 1, no. 5, pp. 69-76, 2001.

[8] H. N. Nagarajan, H. Kotrappa, C. Mallanna, and V. C. Venkatesh, "Mechanics of Flow Forming," CIRP Ann Manuf Technol, vol. 30, no. 1, pp. 159-162, 1981.

[9] M. Joseph Davidson, K. Balasubramanian, and G. R. N. Tagore, "An experimental study on the quality of flowformed AA6061 tubes," J Mater Process Technol, vol. 203, no. 1, pp. 321-325, 2008.

[10] M. J. Roy, R. J. Klassen, and J. T. Wood, "Evolution of plastic strain during a flow forming process," J Mater Process Technol, vol. 209, no. 2, pp. 1018-1025, 2009. 
[11] P. J. Withers and H. K. D. H. Bhadeshia, "Residual stress. Part 2 - Nature and origins," Materials Science and Technology, vol. 17. pp. 366-375, 2001.

[12] C. C. Wong, A. Danno, K. K. Tong, and M. S. Yong, "Cold rotary forming of thin-wall component from flatdisc blank," J Mater Process Technol, vol. 208, no. 1, pp. 53-62, 2008.

[13] C. C. Wong, J. Lin, and T. A. Dean, "Effects of roller path and geometry on the flow forming of solid cylindrical components," J Mater Process Technol, vol. 167, no. 2, pp. 344-353, 2005.

[14] F. A. Hua, Y. S. Yang, Y. N. Zhang, M. H. Guo, D. Y. Guo, W. H. Tong, and Z. Q. Hu, "Three-dimensional finite element analysis of tube spinning," $J$ Mater Process Technol, vol. 168, no. 1, pp. 68-74, 2005.

[15] M. E. Fitzpatrick, A. . Fry, P. Holdway, F. . Kandil, J. Shackleton, and L. Suominen, "Determination of Residual Stresses by X-ray Diffraction - Issue 2," Teddington, 2005.

[16] J. R. Santisteban, M. R. Daymond, J. A. James, and L. Edwards, "ENGIN-X: a third-generation neutron strain scanner," J Appl Crystallogr, vol. 39, no. 6, pp. 812-825, Nov. 2006.

[17] M. T. Hutchings, Withers.P.J, T. M. Holden, and T. Lorentzen, Introduction to characterization of residual stress by neutron diffraction, vol. 8. Taylor \& Francis Group, 2005.

[18] B. GÜN and I. GÜVEL, "Rifling by flow forming," 2007 . 
TABLES

\begin{tabular}{ccccccccc}
\hline $\mathrm{C}$ & $\mathrm{M}$ & $\mathrm{P}$ & $\mathrm{S}$ & $\mathrm{Si}$ & $\mathrm{Cr}$ & $\mathrm{Ni}$ & $\mathrm{Cu}$ & $\mathrm{Nb}$ plus $\mathrm{Ta}$ \\
\hline 0.07 & 1.00 & 0.04 & 0.03 & 1.00 & 15.0 & 5.0 & 3.00 & 0.30 \\
\hline
\end{tabular}

Table 1: Nominal chemical composition of 15-5PH martensitic stainless steel (wt. \%)

\begin{tabular}{ccccccc}
\hline Part ID & $\begin{array}{c}\text { No. of } \\
\text { Pass }\end{array}$ & Initial Thickness & Final Thickness & $\begin{array}{c}\text { Reduction in } \\
\text { Thickness }\end{array}$ & $\begin{array}{c}\text { Initial } \\
\text { Length }\end{array}$ & $\begin{array}{c}\text { Final } \\
\text { Length }\end{array}$ \\
\hline 1-Preform & 0 & \multicolumn{2}{c}{$15 \mathrm{~mm}$} & 0 & \multicolumn{1}{c}{$140 \mathrm{~mm}$} \\
\hline 2 & 1 & $15 \mathrm{~mm}$ & $12 \mathrm{~mm}$ & $3 \mathrm{~mm}(20 \%)$ & $140 \mathrm{~mm}$ & $176 \mathrm{~mm}$ \\
\hline 3 & 1 & $15 \mathrm{~mm}$ & $9 \mathrm{~mm}$ & $6 \mathrm{~mm}(40 \%)$ & $140 \mathrm{~mm}$ & $218 \mathrm{~mm}$ \\
\hline
\end{tabular}

Table 2: Geometrical details of preform and flow formed samples

FIGURES

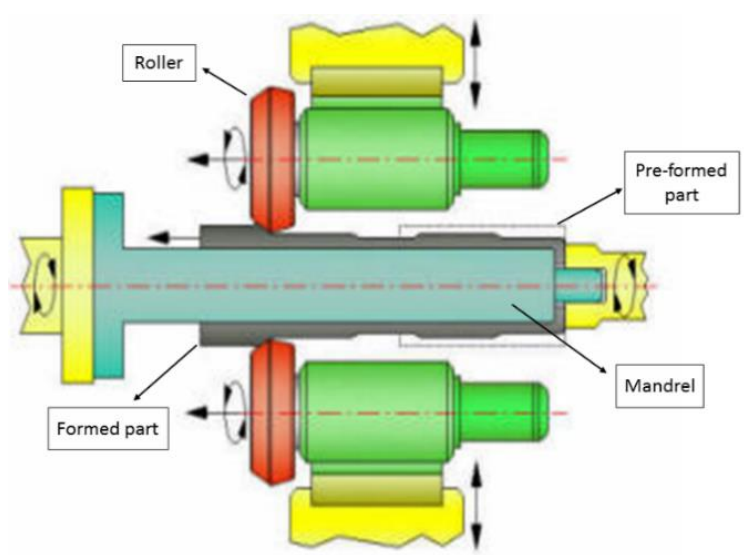

Figure 1: Schematic illustration of forward flow forming process [18]

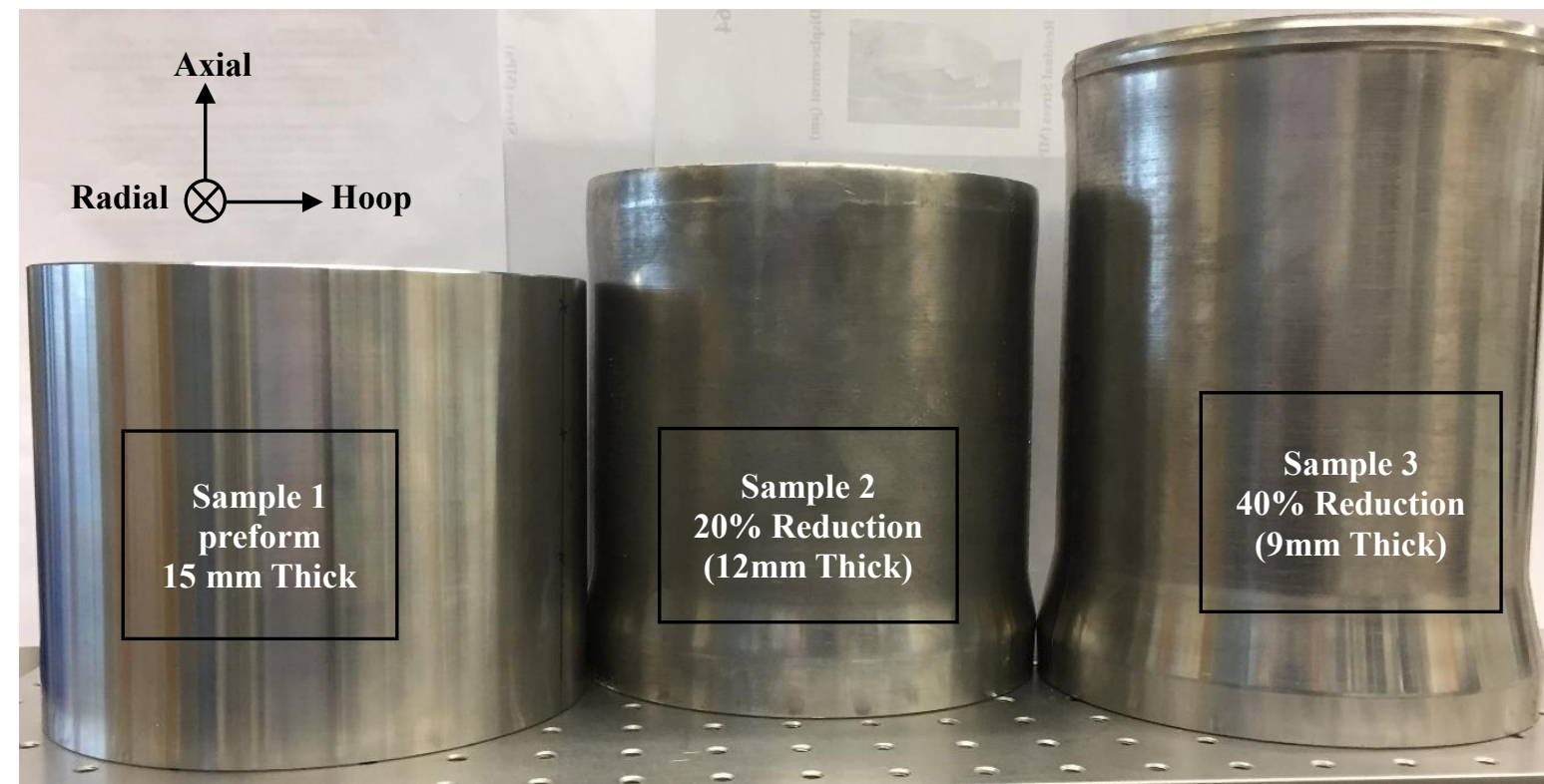

Figure 2: Photograph of the preform and the flow formed samples deformed for $20 \%$ and $40 \%$ of the initial thickness. 


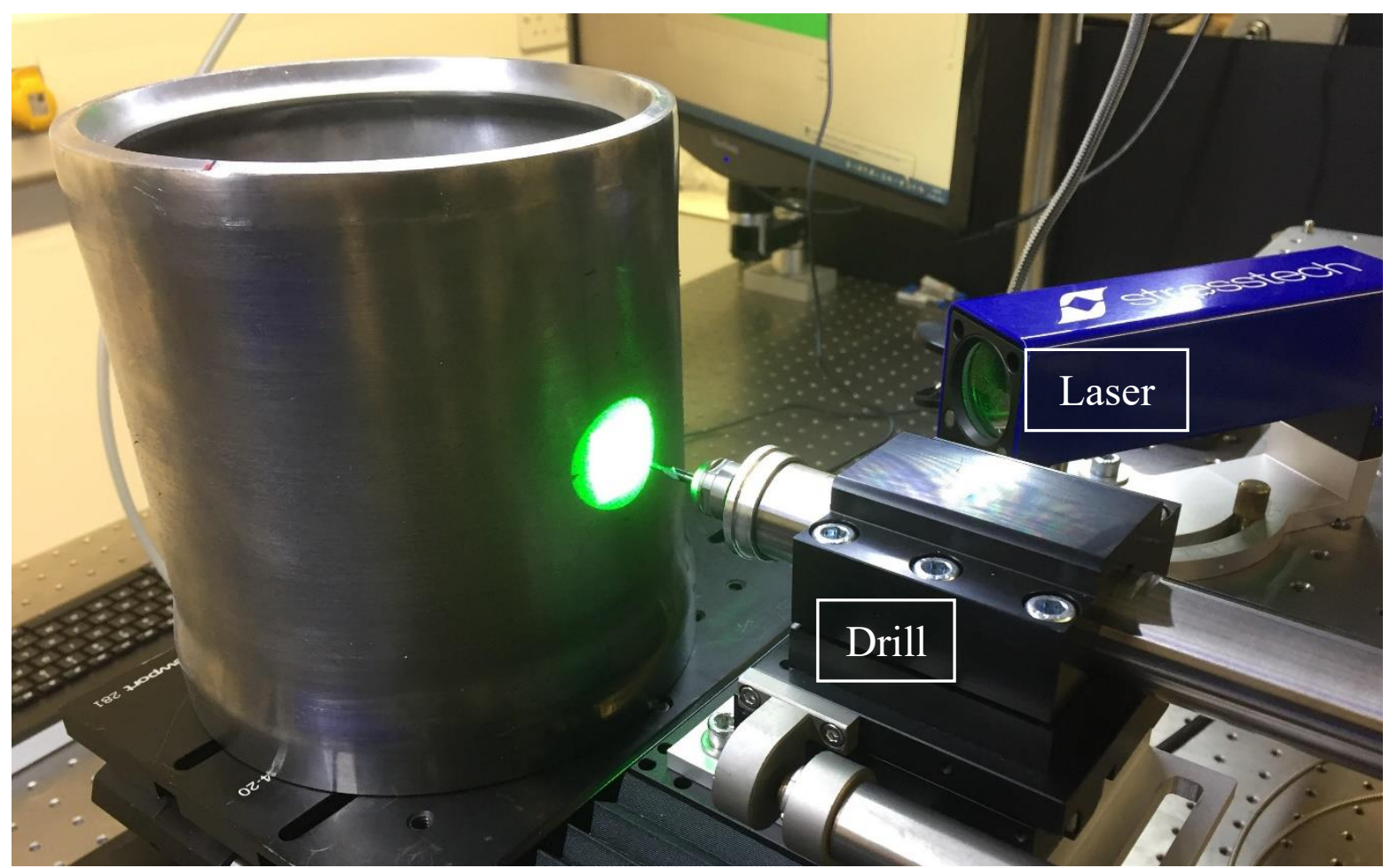

Figure 3: Experimental set-up and the arrangement of ESPI based hole-drilling device for measuring residual stress

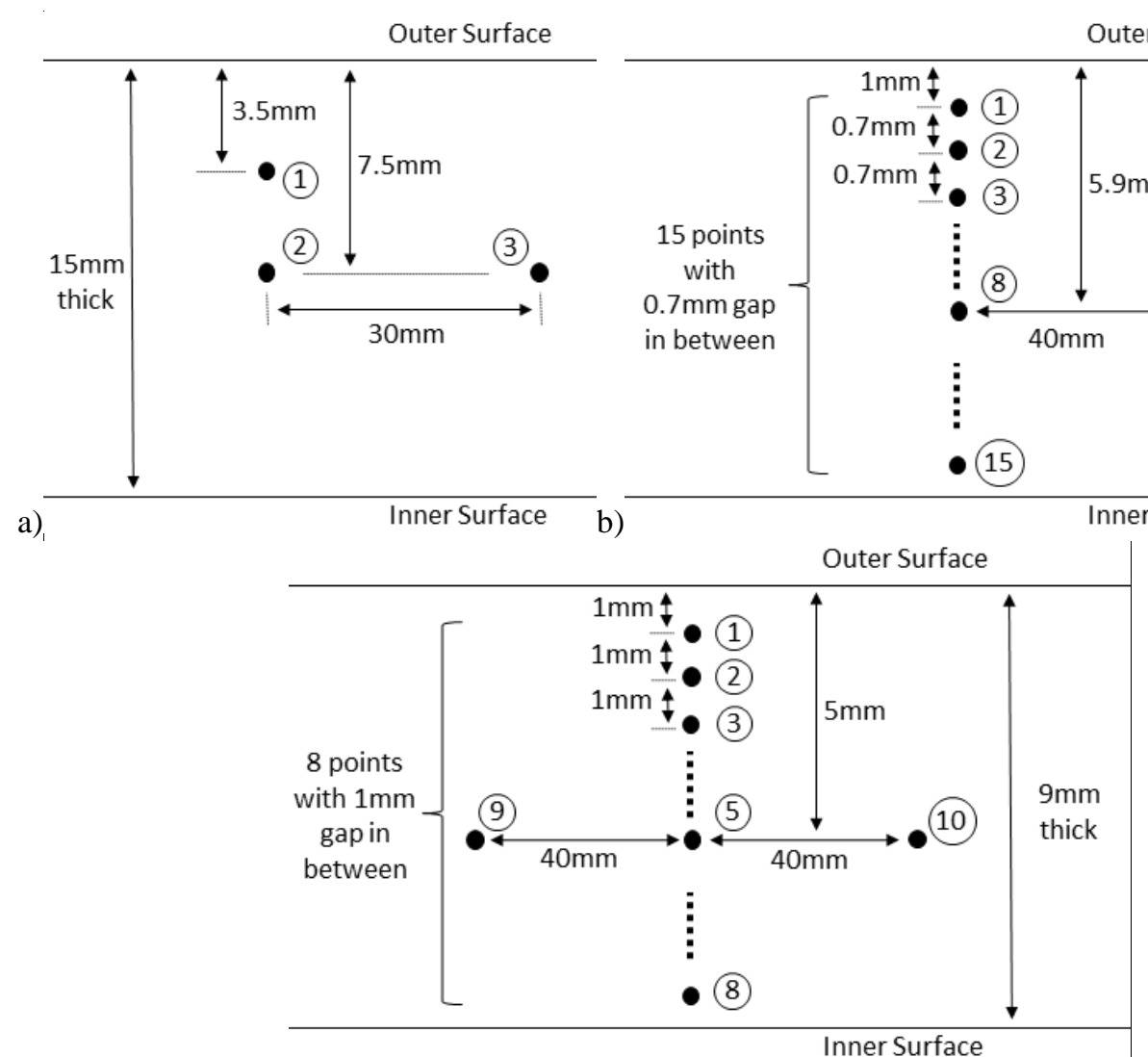

Figure 4: Schematic illustration of the location of points measured by neutron diffraction. a) Preform, b) Sample 2 (20\% reduction), c) Sample 3 (40\% reduction). 


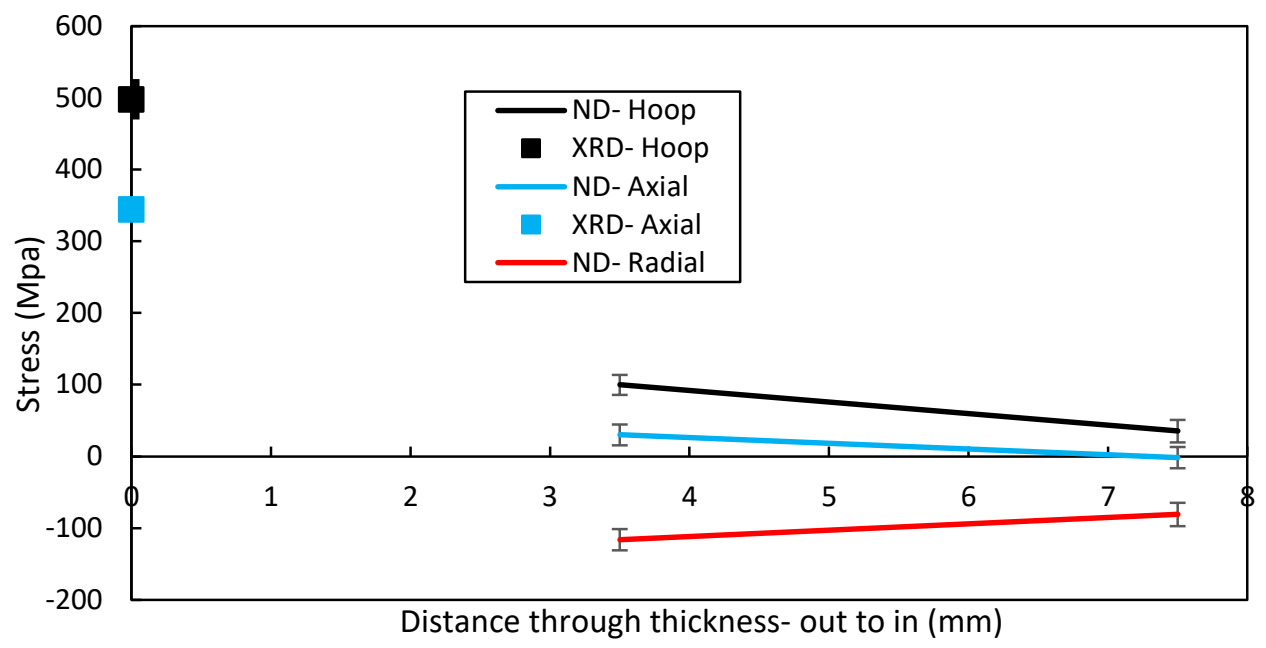

Figure 5: Measured surface and through thickness residual stresses by XRD and neutron diffraction respectively, on the preform.

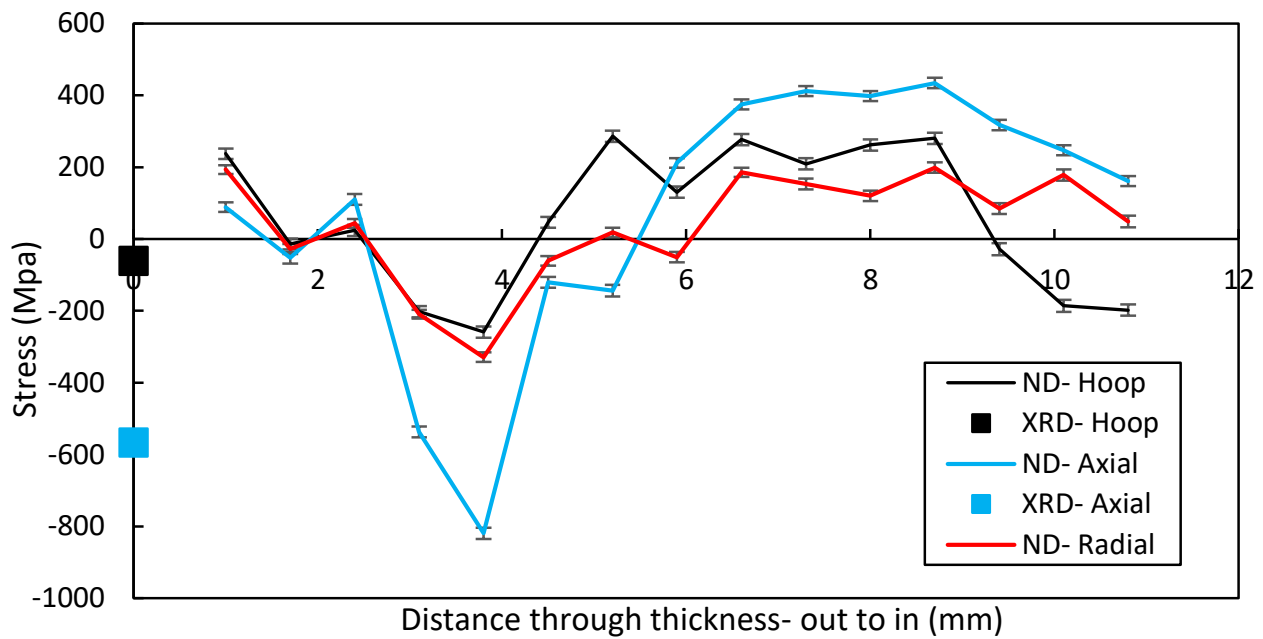

Figure 6: Measured surface and through thickness residual stresses by XRD and neutron diffraction respectively, on the formed sample 2 with $12 \mathrm{~mm}$ wall thickness $(20 \%)$.

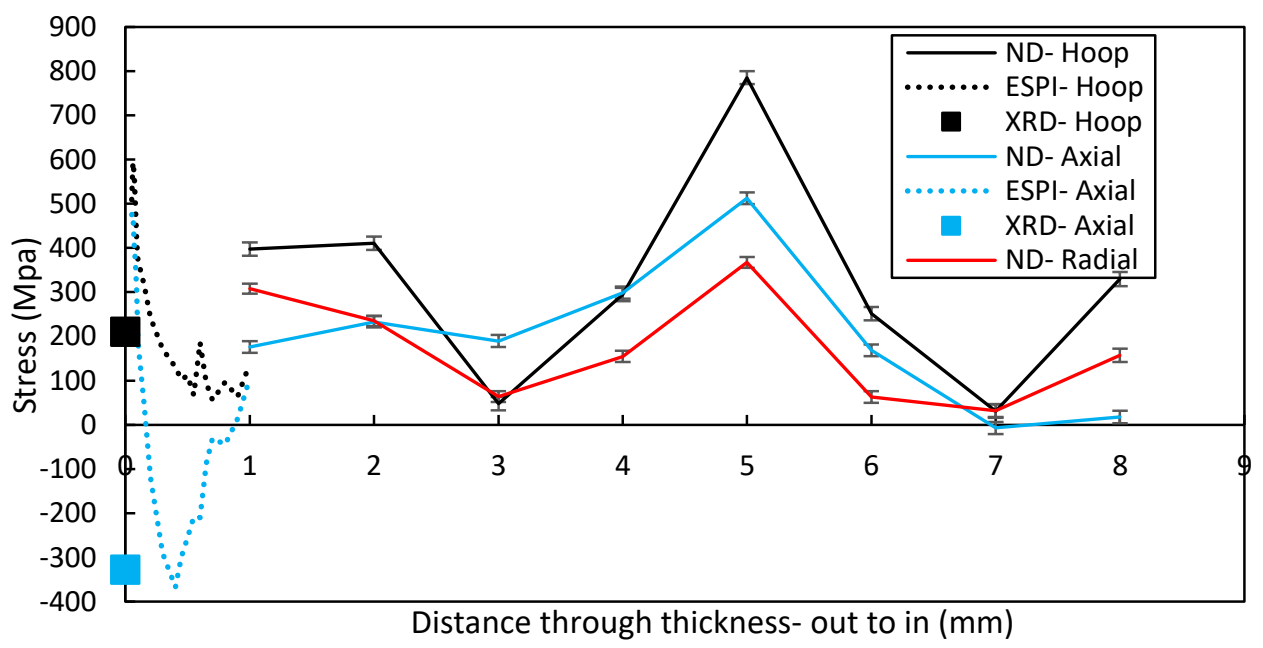

Figure 7: Measured surface and through thickness residual stresses by XRD, ESPI and neutron diffraction respectively, on the formed sample 3 with $9 \mathrm{~mm}$ wall thickness $(40 \%)$. 


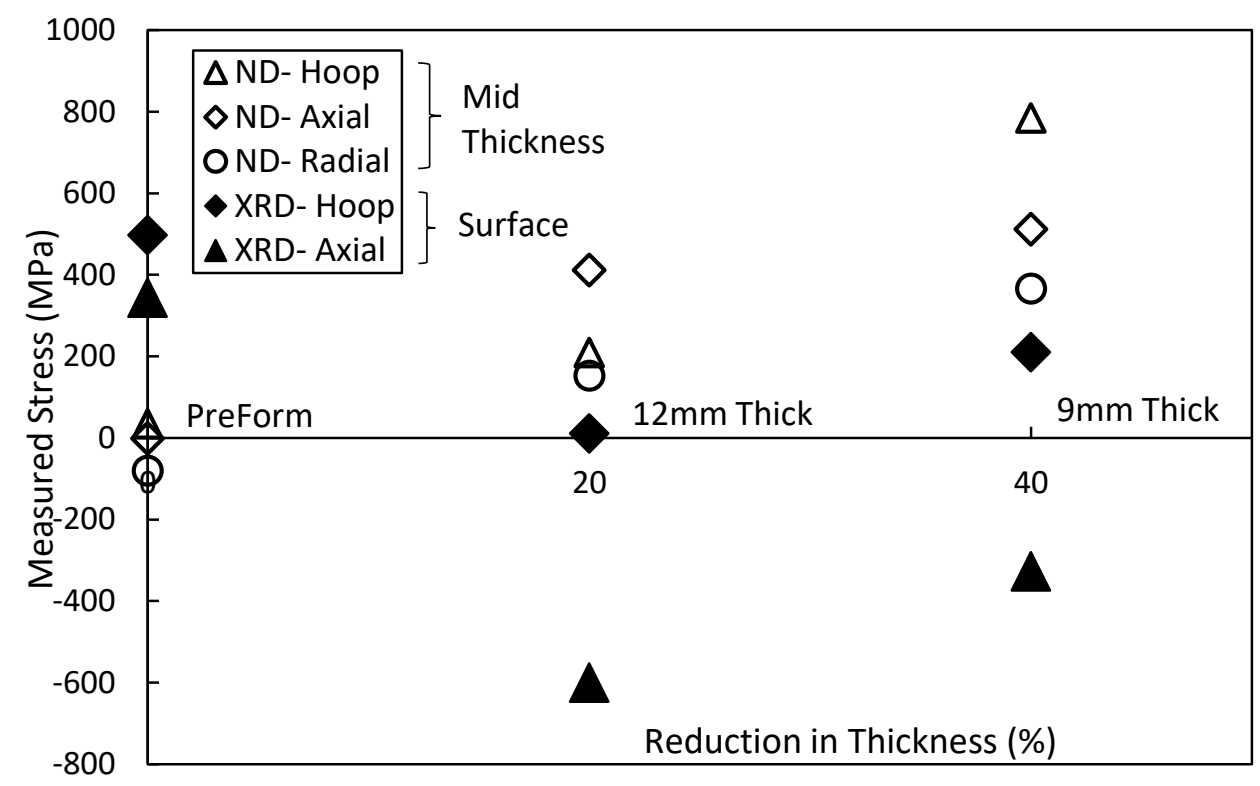

Figure 8: Evolution of residual stress as a function of reduction in the sample thickness by flow forming. Data measured by neutron diffraction are for the middle of the thickness, and data measured by XRD are for the outer surface.

a)
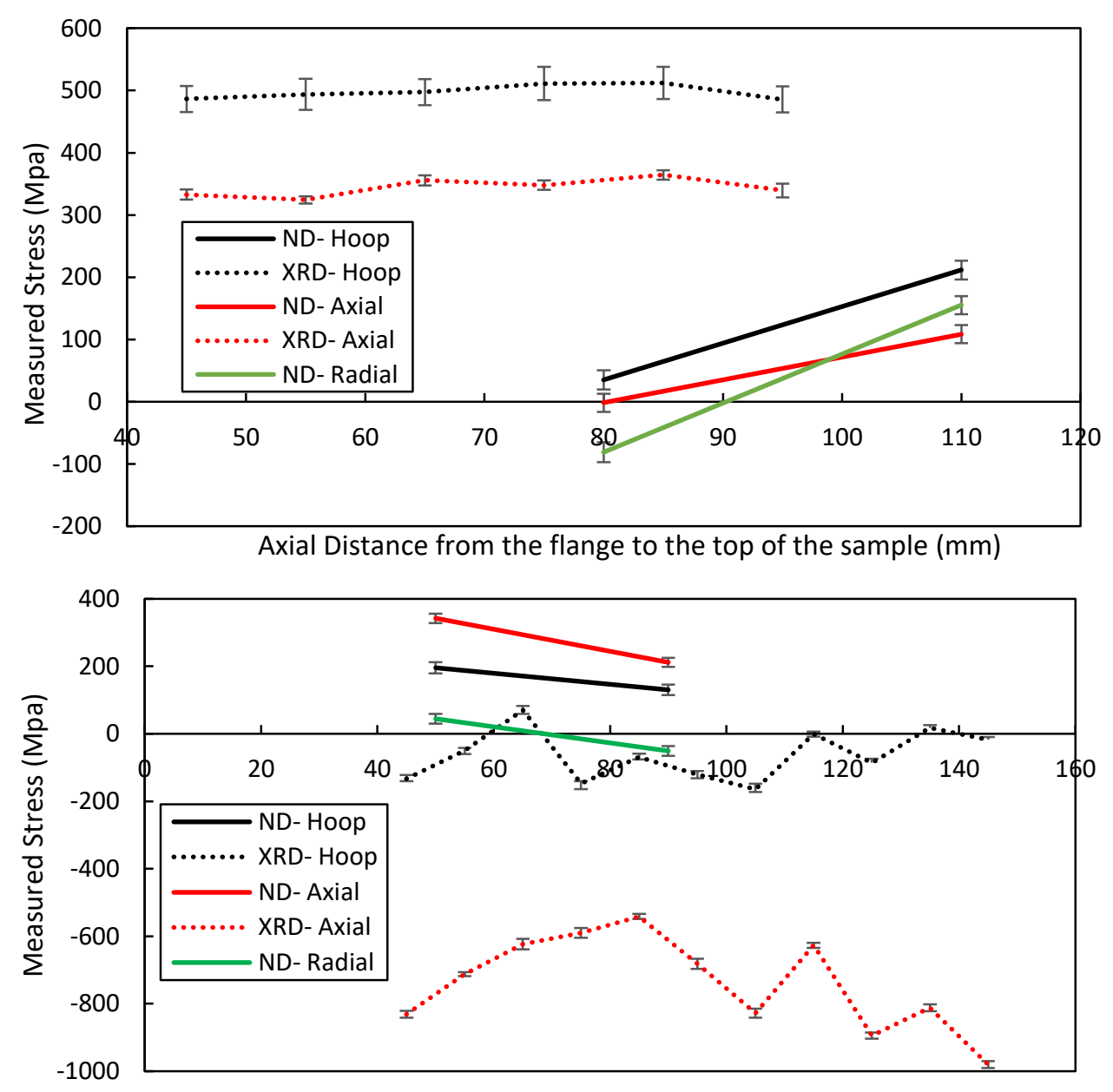

b)

Axial Distance from the flange to the top of the sample $(\mathrm{mm})$ 


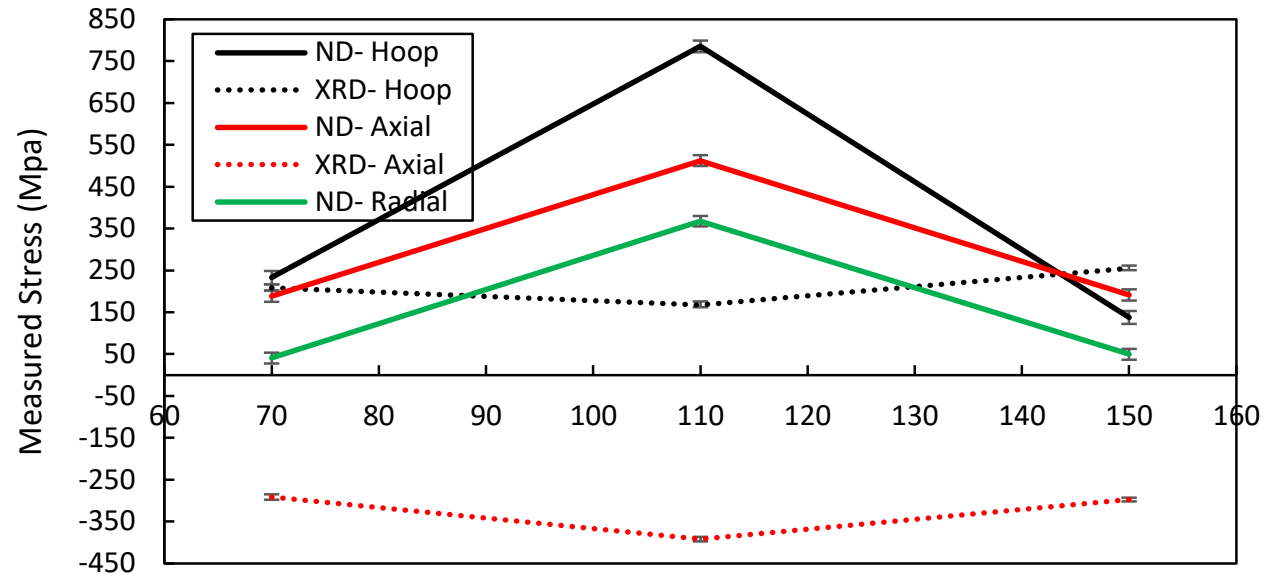

c)

Axial Distance from the flange to the top of the sample $(\mathrm{mm})$

Figure 9: Residual stress profile on the surface (XRD) and middle of the thickness (neutron diffraction) along the length of the samples. a) Preform, b) Sample 2 (20\% reduction), c) Sample 3 (40\% reduction ). 